\title{
Transmission of SARS-CoV-2 During Air Travel: A Descriptive and Modelling Study
}

Jinjun Zhang ( $\nabla$ zhang92560@163.com )

Beijing Emergency Medical Center https://orcid.org/0000-0001-8185-2173

\section{Fei Qin}

University of Chinese academy science

Jianren Li

Beijing Emergency Medical Center

Sijia Tian

Beijing emergency medical center

Jing Lou

Beijing emergency medical center

\section{Xuqin Kang}

Beijing Emergency Medical Center

\section{Huixin Lian}

Beijing emergency medical center

\section{Shengmei Niu}

Beijing emergency medical center

\section{Wenzhong Zhang}

Beijing emergency medical center

\section{Yuguo Chen}

Shandong University Qilu Hospital

\section{Research Article}

Keywords: SARS-CoV-2, COVID-19, Infectious diseases, Transmission, Aircraft, Airtravel

Posted Date: October 28th, 2020

DOI: https://doi.org/10.21203/rs.3.rs-96911/v1

License: (9) This work is licensed under a Creative Commons Attribution 4.0 International License. Read Full License 
Version of Record: A version of this preprint was published at Annals of Medicine on January 1st, 2021. See the published version at https://doi.org/10.1080/07853890.2021.1973084. 


\section{Transmission of SARS-CoV-2 during air travel: a descriptive and modelling study}

Jinjun Zhang ${ }^{1,2^{*}}$, Fei Qin ${ }^{3}$, Jianren $\mathrm{Li}^{2}$, Sijia Tian², Jing Lou ${ }^{2}$, Xuqin Kang ${ }^{2}$, Huixin Lian$^{2}$, Shengmei $\mathrm{Niu}^{2}$, Wenzhong Zhang ${ }^{2}$, Yuguo Chen ${ }^{4 *}$

\section{Author Affiliations:}

${ }^{1}$ School of Medicine, Shandong University, Jinan, Shandong 250012, China (JJ Zhang MD)

${ }^{2}$ Beijing Emergency Medical Center, Beijing 100031, China (JR Li MD, SJ Tian MD, J Lou MD, XQ Kang PhD, HX Lian MD, SM Niu MD, JJ Zhang MD, WZ Zhang MD)

${ }^{3}$ School of Electronic Electrical and Communication Engineering, University of Chinese Academy of Sciences, Beijing, 100049, China (F Qin PhD)

${ }^{4}$ Emergency Department, Qilu Hospital, Shandong University, Jinan, Shandong, 250012, China; Shandong Provincial Clinical Research Center for Emergency and Critical Care Medicine, Jinan, Shandong, 250012, China (Prof YG Chen)

J Zhang, F Qin and J Li contributed equally to this article.

*Corresponding Authors: Dr Jinjun Zhang, Beijing Emergency Medical Center, Beijing 100031, China (zhang92560@163.com); Prof Yuguo Chen, Emergency Department, Qilu Hospital, Shandong University, Jinan, Shandong, 250012, China (chen919085@126.com).

Word count:2464 words. 


\section{Abstract}

Background Millions of cases of the novel coronavirus disease 2019 (COVID-19) have been reported in the world. Although it is known that the air travel has the potential to spread SARS-CoV-2, the risk of in-flight transmission is unknown.

Methods We enrolled all passengers and crew suspected of being infected with SARSCoV-2, who bounded for Beijing on international flights. We specified the characteristics of all confirmed cases of COVID-19 infection and utilized Wells-Riley equation to estimate the infectivity of COVID-19 during air travel.

Results We screened 4492 passengers and crew with suspected COVID-19 infection, verified 161 confirmed cases (mean age 28.6 years), and traced two confirmed cases who may have been infected in the aircraft. The estimated infectivity was 375 quanta/h (range 274-476), while the effective infectivity was only 4 quanta/h (range 2-5). The risk of per-person infection during a 13 hours air travel in economy class was $0.56 \%$ (95\% CI $0.41 \%-0.72 \%)$.

Conclusion We found that the universal use of face masks on the flight, together with the plane's ventilation system, significantly decreased the infectivity of COVID-19.

Keywords: SARS-CoV-2, COVID-19, Infectious diseases, Transmission, Aircraft, Airtravel, 


\section{Introduction}

The SARS-CoV-2 pandemic has caused unprecedented public health problems and economic disruption, especially travel. ${ }^{1-3}$ Given the serious risk of importation of COVID-19 cases during the pandemic, many countries have abated or canceled outbound flights according to the International Air Transport Association (IATA). By the first quarter of 2020, global air travel has slumped by 70 percent and European flights have dropped by 90 percent. ${ }^{4-6}$ The Chinese government suspended outbound flights from other countries in March, and all international flights bound for Beijing have been diverted to 12 designated cities in mainland China since March 23, $2020 .^{7}$ With the development of globalization and the convenience of international air transportation, delineation of the characteristics and potential routes of transmission of SARS-CoV-2 in aircraft is expedient. Research on imported cases by air travel is exceedingly rare, and it is unclear whether SARS-CoV-2 is transmitted by droplets or aerosols. Urgent questions that need to be addressed include how SARS-CoV-2 spreads in aircraft, whether healthy passengers will be infected by infectious patients in nearby seats, and the characteristics of imported cases of COVID-19 infection from overseas. Given that, we collected data on the passengers bound for Beijing to infer whether passengers might be infected during air travel, described the characteristics of the confirmed cases and estimated the infectivity of COVID-19 during air travel.

The reproduction number (R0) has been widely utilized to evaluate the risk of large scale outbreak, ${ }^{5,8-9}$ but R0 is less capable to represent the infectivity risk in short time 
scale within a confined space, such as air travel last only a few hours. As reported, the quantitative microbial risk assessment method has been employed to model and predict the risk of infection for seasonal influenza, influenza A (H1N1) and Middle East respiratory syndrome coronavirus (MERS-CoV), where the infectivity is quantified with infectious quanta released by one source case per hour. ${ }^{10-11}$ Quantum was defined as the necessary infectious droplets or aerosols to infect $\left(1-\mathrm{e}^{-1}\right)$ exposed individuals. Herein, we used the classic Wells-Riley equation with collected data to estimate the infectivity of COVID-19 during air travel, the rate of quantum generation for COVID19, which can be utilized to evaluate the infection risk during air travel under various scenarios. $^{12}$

\section{Methods}

Study design and participants

We enrolled passengers and crew suspected with COVID-19 infection who were bound for Beijing Capital International Airport (PEK) via international flights from March 1 to March 31, 2020. Passengers and crew were defined as a confirmed case with COVID-19 infection according to the new coronavirus pneumonia diagnosis and treatment program published by the National Health Commission of the People's Republic of China. ${ }^{13}$ We collected the medical record including demographic, epidemiological, clinical, laboratory testing for COVID-19, cluster case, and outcome information. Other data were collected from publicly available sources. Clinical outcomes were followed up to August 1, 2020. 
The study was approved by Ethics Committee of Beijing Emergency Medical Center (No. 2020-01), and written informed consent was waived.

\section{Procedures}

PEK is one of the largest airports in the world. To effectively prevent the outbreak of COVID-19, PEK designated T3 terminal D (T3-D) as a special area for international aircraft docking. All passengers on board reported the health on arrival. When a flight stopped at T3-D, all passengers underwent health quarantine inspection again, including body temperature screening, and health declaration. The healthy passengers were transferred to the designated temporary place of isolation for 14 days of medical observation, while others suspected of having COVID-19 infection were transferred to the designated hospitals where reverse-transcriptase polymerase-chain-reaction (RTPCR), chest radiograph, and blood routine were performed (figure 1).

\section{Statistical analysis}

We transferred all passengers with suspected COVID-19 infection to the designated hospitals for coronavirus nucleic acid detection. We analyzed each laboratoryconfirmed case with epidemiologically confirmed links by contact tracing to infer whether the patient had been infected during air travel. Continuous variables were expressed as means and standard deviations, and the categorical variables were presented as percentages in each category. All statistical analyses were performed with SPSS software version 22.0 (SPSS, Chicago, IL, USA). 
The analyses output were further processed with non-steady Wells-Riley equation to estimate the quanta release rate of COVID-19. We modelled the accumulation of infectious quanta with ordinary differential equation:

$$
v S \frac{d N}{d t}=I \alpha q-N Q
$$

where $N$ is the concentration of quanta in the confined cabin, $S$ is the number of susceptible in the cabin, $v$ is the averaged space for each individual, $I$ is the number of infectors, and $q$ is the quantum generation rate. We assumed all passengers in the cabin being well equipped with face masks, which contributed to $\alpha$ as an absorption ratio on released quanta. We also assumed all the airline operators have maximized the filtering capability of ventilation system in the flight, which contributed to $Q$ as an equalized air exchange rate with both filtering and replace effect. The above equation modelled the fact that the accumulation of quanta is equal to the generated quanta by infectors minus removed quanta by ventilation system. With simple algebra, the average number of quanta breathed by one susceptible can be derived:

$$
\bar{\mu}=\beta \frac{I \alpha q p t}{Q}\left[1-\frac{v S}{Q t}\left(1-e^{-\frac{Q t}{v S}}\right)\right]
$$

where $p$ is the breathing rate, $\beta$ is also contributed by face mask to decrease the breathed quanta. With the original definition of quantum, the probability of infection during the flight were modelled as:

$$
P=\frac{D}{S}=1-e^{-\bar{\mu}}=1-e^{-\beta \frac{I \alpha q p t}{Q}\left[1-\frac{v S}{Q t}\left(1-e^{-\frac{Q t}{v S}}\right)\right]}
$$

With the investigation results, the confirmed cases as well as their contact tracing were identified. The number of passengers and flight time were obtained through public 
source. We assumed an averaged space of $2 \mathrm{~m}^{3}$ for each passenger in the flight, an averaged breathing rate of $0.3 \mathrm{~m}^{3} / \mathrm{h}$, an averaged air exchange ratio of 25 times per hour with $99.99 \%$ HEPA filtering efficiency, and the face mask efficiency to prevent quanta releasing and absorption of $90 \%$. The quantum generation rate of COVID-19, i.e. $\mathrm{q}$ can then be estimated, which can be further utilized to predict infection risk in various scenarios. All estimations and predictions were performed with Matlab (version R2016a).

\section{Results}

From March 1 to March 31, 2020, a total of 130000 passengers arrived at PEK by more than 830 international flights, an average of 156 passengers per flight. Almost every passenger used a face mask to protect themselves, and some even wore medical protective clothing and goggles during air travel. In total, 4492 (3.4\%) of 130000 passengers were screened for symptoms of COVID-19 infection on arrival at PEK and isolated for 14 days of medical observation in the designated place of isolation; 161 (3.6\%) passengers were verified as laboratory-confirmed cases of COVID-19 infection during quarantine $(131,81.4 \%)$ and medical observation $(30,18.6 \%)$ (figure 2). Of 830 international flights, 94 (11.2\%) carried confirmed cases. In these 94 flights, 64 (68.1\%) flights had only one confirmed case and 30 (31.9\%) flights had at least two. The overall number of confirmed cases in these 30 flights was 97, making a total of 161 confirmed cases. The number of confirmed cases in these 30 flights ranged from 2 to 11 per flight (table 1). Specifically, eleven patients confirmed to have COVID-19 had close contact 
history and came from four families in the same aircraft, a Boeing 787-9 from Madrid to Beijing with flight duration of 10 hours 18 minutes. However, no passengers seated within two rows of the confirmed cases were infected during air travel (figure 3). After investigation, sixty-four of 97 confirmed cases had ascertained epidemiological links by contact tracing before boarding, twenty-nine confirmed cases had symptoms before boarding, and two confirm cases had contact with fever patient before boarding. Only two $(1.2 \%)$ confirmed cases were unable to determine where, when, and how they were infected, nor could they be excluded from being infected in the aircraft (figure 4A).

We assumed these two confirmed cases as indeed infected during the air travel (D), the sixty-four confirmed cases with close contact as infectors during the air travel (I), and all other confirmed cases as randomization following Bernoulli(0.5) distribution constrained by at least one infector in the flight. Figure 4B shows the estimated $q$ with maxim likelihood estimation, about 375 quanta per hour (range 274-476). As a comparison, the infectivity of H1N1 was reported about 100 quanta per hour (range 79128), while about 50 quanta per hour (range 6-140) for MERS-CoV. This demonstrated the significantly increased infectivity for COVID-19, while was less capable to character the per person risk during the flight. An intuitive variation of $q$, the effective infectivity can be defined with $q_{e}=\alpha \beta q$, which was only 4 quanta per hour (range 25). The extremely low effective quanta will result in an expectation of per-person infection risk at only $0.56 \%$ o $(95 \%$ CI $0.41 \%$ - $0.72 \%$ ) during a 13 hours air travel in economy class with one infector, or equalized 0.17 infected individuals (figure 4B). As a comparison, if all the passengers were not carefully protected with face masks, the 
number of infected individuals could be roughly 6 for a 5 hours flight, and 17 for a 13 hours flight in economy class. If the passengers travel in first class, larger space with less passengers, the number of infected individuals could be 3 for 5 hours flight and 8 for 13 hours flight. But the per-person risk for the passengers travel with first class would be higher given the same constraint of one infector in the cabin. In detail, the per-person risk during a 13 hours flight in first class could be 2.2\%o (figure 5), which is about four times higher than travel in the economy class.

Regarding the origin of the 161 confirmed cases, the foremost countries were England $(53,32.9 \%)$, Spain $(46,28.5 \%)$, Italy $(18,11.2 \%)$, United States $(17,10.5 \%)$, and France $(7,4.3 \%)$. Most patients $(99,61.5 \%)$ were female, the mean age was 28.6 years (range 1-70), and $53(32.9 \%)$ patients were students. Sixty-five (40.4\%) patients had direct exposure to a confirmed case, 77 (47.8\%) had epidemiological contact history. 57 were associated with clustering involving at least two confirmed cases in a family or other places of close contact within 14 days, and 40 (24.8\%) had familial clustering. Forty $(24.8 \%)$ patients were asymptomatic during the flights while 121 (75.2\%) had symptoms of respiratory infection, the most common symptoms were cough (34.8\%), fever (32.9\%), and fatigue (14.3\%). The mean time from arrival to illness onset was 2.4 days, and from arrival to confirmed infection 2.7 days (table 2). By August 1, 2020, all 161 patients had been discharged, no died.

\section{Discussion}


During the COVID-19 pandemic, human-to-human transmission has been reported by many research groups, especially from asymptomatic cases to close contacts. ${ }^{14-17}$ In this study, we reported 161 laboratory-confirmed cases from 4492 passengers with suspected COVID-19 infection, and by epidemiological investigation inferred whether these passengers might have been infected during air travel. Our findings suggest that the universal use of face masks on the flight, together with the airplane's ventilation system, likely prevented all secondary cases of COVID-19.

Previous studies reported that passengers on aircraft were prone to infection during epidemics of respiratory infectious diseases, including Severe Acute Respiratory Syndrome (SARS), Middle East Respiratory Syndrome (MERS), and influenza A (H1N1). ${ }^{18-20}$ In theory, in-flight transmission of COVID-19 could occur via direct physical contact, droplet spread, aerosol, and suspended small particles. ${ }^{21}$ In this study, we found only two patients confirmed as infected who might have acquired the infection during the flight or the incubation period before boarding. The reasons for the low infection risk may be as follows. Firstly, almost every passenger and crew member used a face mask as a tool to stem transmission in cabins during air travel. Although some passengers would have had to remove their mask to eat and drink, we did not find any evidence that passengers might be infected in this regard. Secondly, the air circulation pattern on the aircraft is side to side (laminar): air enters the cabin from the top, circulates across the aircraft, and exits the cabin near the floor (figure 3 ), ${ }^{22}$ a pattern which can effectively prevent respiratory infectious disease in cabins. Thirdly, control measures conducted at the airport played an important role. PEK designated T3-D as a 
special area for international aircraft docking, where all passengers suspected with COVID-19 infection were screened through quarantine inspection, laboratory testing for COVID-19, and isolation and medical observation for 14 days. These control measures were very effective for containment of COVID-19. ${ }^{23-24}$

Other studies on the clinical characteristics of COVID-1925-26 have reported that most patients with confirmed infection presented with fever, cough, and fatigue. However, in our study only $32.9 \%$ of confirmed patients had fever. Therefore, our findings indicate that temperature screening alone is not an effective way to contain the spread of COVID-19 at exit or entry ports for international flights, because infected individuals might be within the incubation period during which they do not express appropriate symptoms or are completely asymptomatic. Most of the confirmed cases were young women, the mean age of passengers was 28.6 years, and $26 \%$ of the cohort were students who were returning to China after the COVID-19 epidemic had begun to recede.

With the consideration of all these factors, we modified the non-steady Wells-Riley equation to better characterize the infectivity of COVID-19 during air travel. The estimated infectivity of COVID-19 was 375 quanta per hour, while the effective infectivity with face mask was only 4 quanta per hour. These results demonstrate two facts: firstly, the infection risk of COVID-19 could be much higher than H1N1(100 quanta per hour) and MERS-CoV(50 quanta per hour). And even though, the second fold reveals the almost negligible risk (4 quanta per hour) with face mask and well 
functioned ventilation system. The estimated infectivity and modified model can be utilized by individuals to evaluate the risk of air travel, and by governments or airlines to guide their operation policy.

\section{Conclusion}

During the pandemic of COVID-19, our findings suggest that the risk of infection in aircraft was negligible. Universal use of face masks on the flight, together with the plane's ventilation system, likely prevented all secondary cases of COVID-19. Personal protection equipment on all flights should be strongly encouraged. 


\section{Acknowledgments}

We thank all the Beijing EMS staff for their efforts in transferring the suspected passengers and confirmed patients in PEK, we thank all patients involved in this study.

\section{Authors' contributions}

JZ, WZ and YC conceived and designed the study. JL, XK, HL and JL collected data. JZ, FQ, SN and ST analyzed data. JZ and FQ wrote the first draft. All authors read and approved the final manuscript.

\section{Ethics approval and consent to participate}

The study was approved by Ethics Committee of Beijing Emergency Medical Center (No.2020-01) and the written informed consent was waived.

\section{Consent for publication}

Not applicable.

\section{Availability of data and materials}

Not applicable.

\section{Competing interests}

The authors declare that they have no competing interests.

\section{Funding}


This study was supported by the Beijing Municipal Science and Technology Project (Z191100004419003), National Key R\&D Program of China (2020YFC0846600), and Shandong Provincial Key Science and Technology Innovation Project (2020SFXGFY03). 


\section{References}

1. Boldog P, Tekeli T, Vizi Z, D énes A, Bartha FA, Röst G. Risk Assessment of Novel Coronavirus COVID-19 Outbreaks Outside China. J Clin Med. 2020;9(2):571-583.

2. Gilbert M, Pullano G, Pinotti F, et al. Preparedness and vulnerability of African countries against importations of COVID-19: a modelling study. Lancet. 2020;395(10227):871-877.

3. Craig AT, Heywood AE, Hall J. Risk of COVID-19 importation to the Pacific islands through global air travel. Epidemiol Infect. 2020;148:e71-76.

4. Xu S, Li Y. Beware of the second wave of COVID-19. Lancet. 2020;395(10233):1321-1322.

5. Leung K, Wu JT, Liu D, Leung GM. First-wave COVID-19 transmissibility and severity in China outside Hubei after control measures, and second-wave scenario planning: a modelling impact assessment. Lancet. 2020;395(10233):1382-1393.

6. IATA. Air Passenger Market Analysis.2020. https://www.iata.org/en/iatarepository/publications/economic-reports/air-passenger-monthly-analysis---feb2020/(accessed August $\quad$ 12, 2020).

7. Xinhuanet. More Beijing-bound flights diverted to stem imported COVID-19 cases.2020. http://en.people.cn/n3/2020/0331/c90000-9674346.html (accessed August 12, 2020).

8. Kucharski AJ, Russell TW, Diamond C, et al. Early dynamics of transmission and control of COVID-19: a mathematical modelling study [published online ahead of print, $2020 \mathrm{Mar}$ 11]. Lancet Infect Dis. 2020; doi:10.1016/S1473-3099(20)30144-4.

9. Li Q, Guan X, Wu P, et al. Early Transmission Dynamics in Wuhan, China, of Novel Coronavirus-Infected Pneumonia. N Engl J Med. 2020;382(13):1199-1207. 
10. Wagner BG, Coburn BJ, Blower S. Calculating the potential for within-flight transmission of influenza A(H1N1). BMC Med 2009, 7: 81.

11. Rudnick SN, Milton DK: Risk of indoor airborne infection transmission estimated from carbon dioxide concentration. Indoor Air 2003, 13:237-245.

12. Wells. On air-borne infection: II--Droplets and droplet nuclei. Am J Hyg 1934, 20:611618.

13. New coronavirus pneumonial diagnosis and treatment program (7th ed.) (in Chinese). http://www.nhc.gov.cn/xcs/zhengcwj/202003/46c9294a7dfe4cef80dc7f5912eb1989.shtml accessed August 12, 2020).

14. 14. Li C, Ji F, Wang L, et al. Asymptomatic and Human-to-Human Transmission of SARSCoV-2 in a 2-Family Cluster, Xuzhou, China. Emerg Infect Dis. 2020;26(7):1626-1628.

15. Zhang J, Tian S, Lou J et al. Familial cluster of COVID-19 infection from an asymptomatic. Crit Care. 2020;24(1):119..

16. Chowell G, Mizumoto K. The COVID-19 pandemic in the USA: what might we expect?. Lancet. 2020;395(10230):1093-1094.

17. Tian S, Hu N, Lou J, et al. Characteristics of COVID-19 infection in Beijing. J Infect. 2020;80(4):401-406.

18. Olsen SJ, Chang HL, Cheung TY, et al. Transmission of the severe acute respiratory syndrome on aircraft. N Engl J Med. 2003;349(25):2416-2422.

19. Coburn BJ, Blower S. Predicting the potential for within-flight transmission and global dissemination of MERS. Lancet Infect Dis. 2014;14(2):99. 
20. Kim JH, Lee DH, Shin SS, et al. In-Flight Transmission of Novel Influenza A (H1N1). Epidemiol Health. 2010;32:e2010006.

21. Young N, Pebody R, Smith G, et al. International flight-related transmission of pandemic influenza A(H1N1)pdm09: an historical cohort study of the first identified cases in the United Kingdom. Influenza Other Respir Viruses. 2014;8(1):66-73.

22. Mangili A, Gendreau MA. Transmission of infectious diseases during commercial air travel. Lancet. 2005;365(9463):989-996.

23. J Lou, SJ Tian, SM Niu, et al. Coronavirus disease 2019: a bibliometric analysis and review. Eur Rev Med Pharmacol Sci, 2020; 24 (6): 3411-3421.

24. Elachola H, Ebrahim SH, Gozzer E. COVID-19: Facemask use prevalence in international airports in Asia, Europe and the Americas [published online ahead of print]. Travel Med Infect Dis. 2020; doi:10.1016/j.tmaid.2020.101637.

25. Tian H, Liu Y, Li Y, et al. An investigation of transmission control measures during the first 50 days of the COVID-19 epidemic in China [published online ahead of print]. Science. 2020; doi:10.1126/science.abb6105.

26. NS Chen, M Zhou, X Dong, et al. Epidemiological and clinical characteristics of 99 cases of 2019 novel coronavirus pneumonia in Wuhan, China: a descriptive study. Lancet. 2020; 395(10223): 507-513. 
Table 1. The top ten flights with confirmed and suspected infection cases

\begin{tabular}{|c|c|c|c|c|c|c|}
\hline Flight & $\begin{array}{c}\text { Model of } \\
\text { Aircraft }\end{array}$ & $\begin{array}{l}\text { Duration of } \\
\text { Flight }\end{array}$ & $\begin{array}{l}\text { Number of } \\
\text { passangers }\end{array}$ & $\begin{array}{c}\text { Number of } \\
\text { confirmed cases }\end{array}$ & $\begin{array}{c}\text { Suspected } \\
\text { infection case }\end{array}$ & AR \\
\hline 1 & $787-9$ & $10 \mathrm{hr} 18 \mathrm{~min}$ & 247 & 11 & 0 & 0 \\
\hline 2 & $747-8$ & $8 \mathrm{hr} 35 \mathrm{~min}$ & 312 & 8 & 0 & 0 \\
\hline 3 & $380-800$ & $6 \mathrm{hr} 53 \mathrm{~min}$ & 369 & 5 & 0 & 0 \\
\hline 4 & $777-300$ & $5 \mathrm{hr} 17 \mathrm{~min}$ & 219 & 5 & 0 & 0 \\
\hline 5 & $787-9$ & $6 \mathrm{hr} 51 \mathrm{~min}$ & 294 & 4 & 0 & 0 \\
\hline 6 & $787-9$ & $10 \mathrm{hr} 12 \mathrm{~min}$ & 240 & 4 & 1 & $4.2 \%$ \\
\hline 7 & $777-300$ & $6 \mathrm{hr} 32 \mathrm{~min}$ & 256 & 4 & 0 & 0 \\
\hline 8 & $330-300$ & $10 \mathrm{hr} 4 \mathrm{~min}$ & 275 & 4 & 0 & 0 \\
\hline 9 & $380-800$ & $6 \mathrm{hr} 44 \mathrm{~min}$ & 352 & 4 & 0 & 0 \\
\hline 10 & $777-300$ & $8 \mathrm{hr} 48 \mathrm{~min}$ & 278 & 3 & 1 & $3.6 \%$ \\
\hline
\end{tabular}


Table 2. Characteristics of 161 patients with COVID-19 infection

\begin{tabular}{|c|c|}
\hline & Case $(n=161)$ \\
\hline \multicolumn{2}{|l|}{ Sex, $n(\%)$} \\
\hline Female & $99(61.5)$ \\
\hline Male & $62(38.5)$ \\
\hline \multicolumn{2}{|l|}{ Age,years } \\
\hline Mean(SD) & $28.6(12.8)$ \\
\hline Range & $1-70$ \\
\hline \multicolumn{2}{|l|}{ Occupation, n(\%) } \\
\hline Crew & $4(2.5)$ \\
\hline Student & $53(32.9)$ \\
\hline Employee & $29(18.0)$ \\
\hline Other & $75(46.6)$ \\
\hline Cluster case, $\mathrm{n}(\%)$ & $57(35.4)$ \\
\hline Family & $40(24.8)$ \\
\hline Other & $17(10.6)$ \\
\hline Contact history, n(\%) & $77(47.8)$ \\
\hline Contact with confirmed case & $65(40.4)$ \\
\hline Contact with suspected case & $12(7.5)$ \\
\hline Asymptomatic, n(\%) & $40(24.8)$ \\
\hline Signs and Symptoms, n(\%) & $121(75.2)$ \\
\hline Fever & $53(32.9)$ \\
\hline Cough & $56(34.8)$ \\
\hline Fatigue & $23(14.3)$ \\
\hline \multicolumn{2}{|l|}{ Time interval, Mean (SD) } \\
\hline From arrival to symptom onset & $2.4(3.1)$ \\
\hline From arrival to confirmed & $2.7(3.1)$ \\
\hline
\end{tabular}


Figures

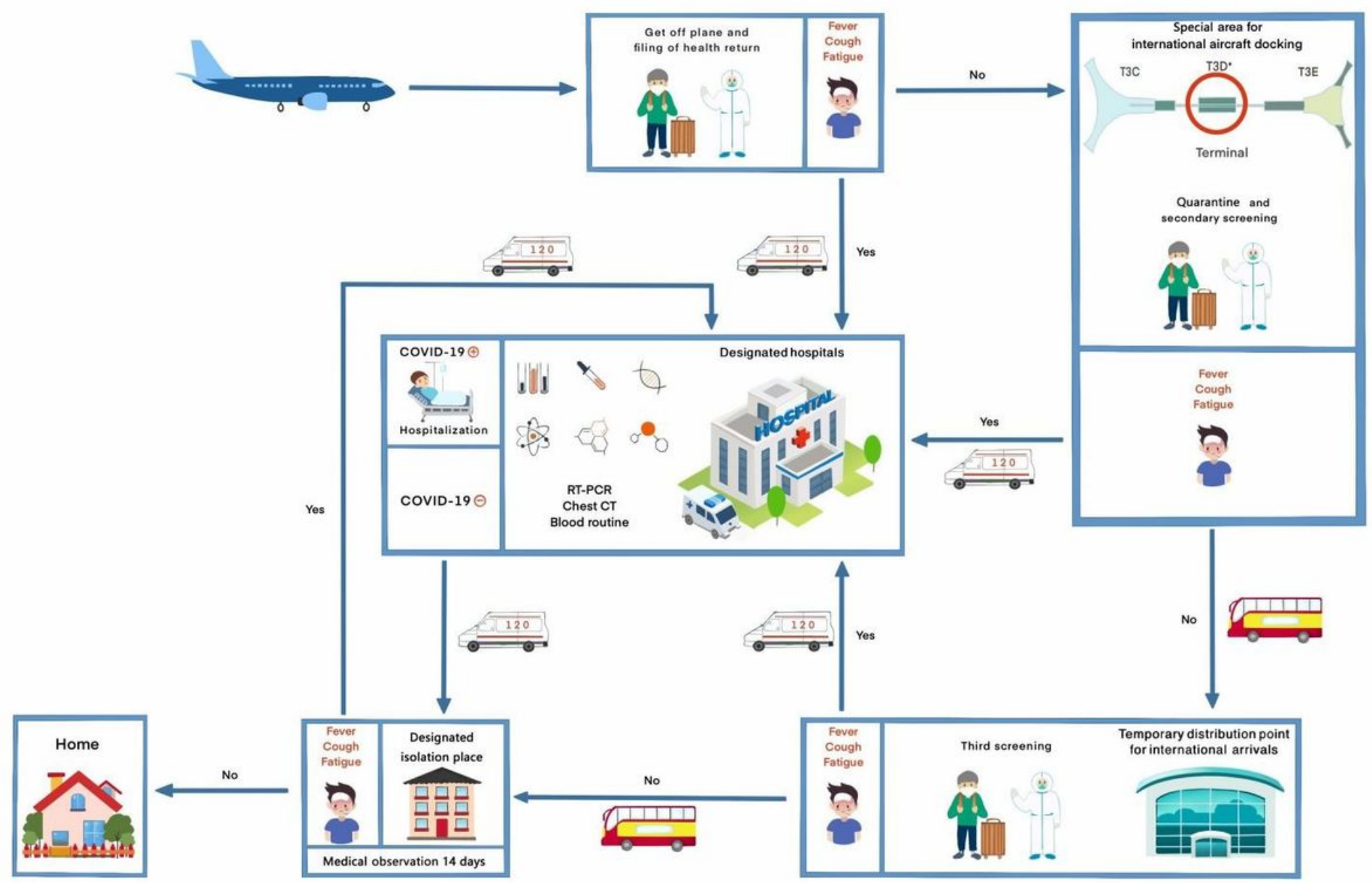

Figure 1

Screening flow 


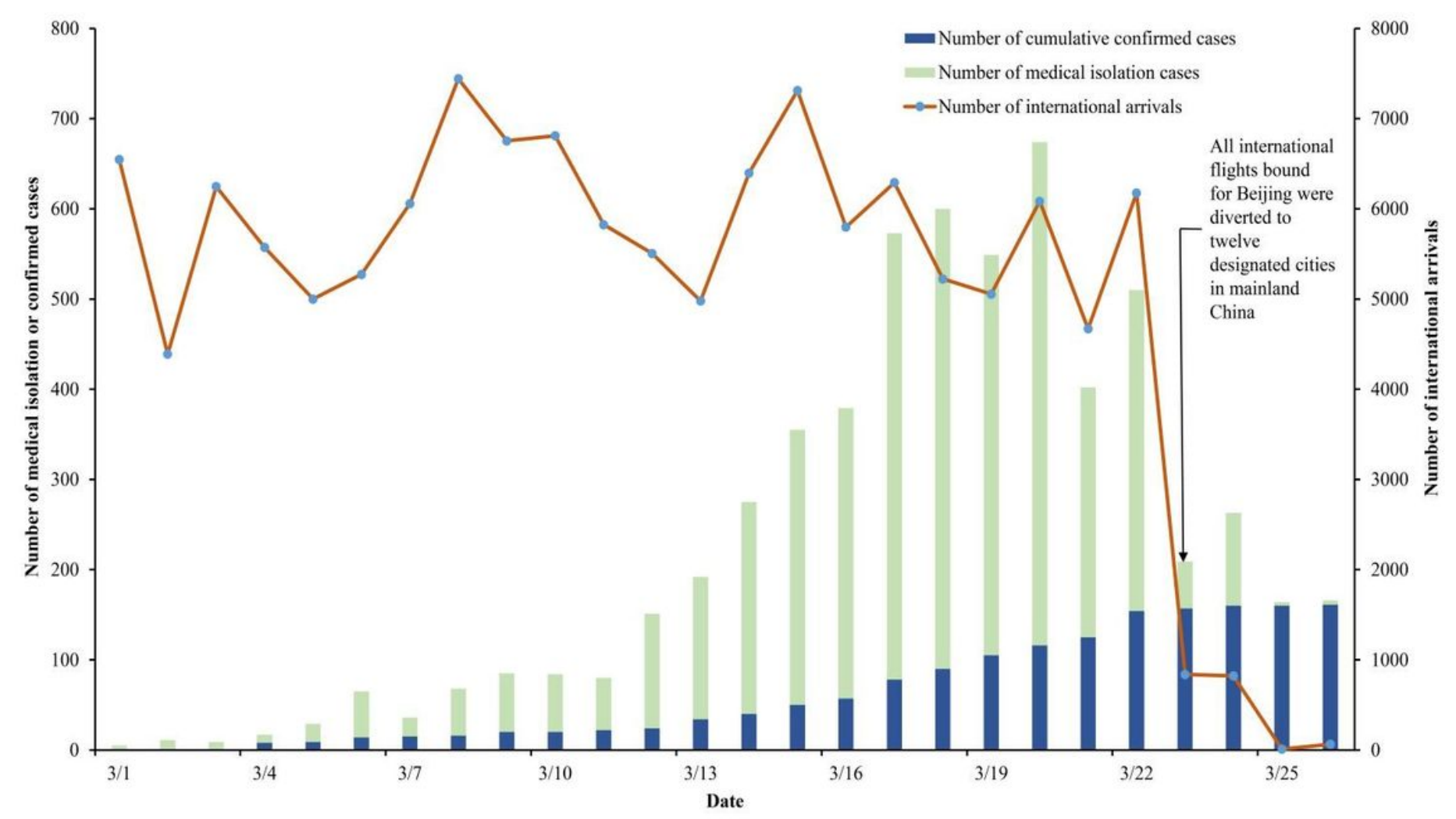

Figure 2

Date of cumulative confirmed cases and medical observation cases

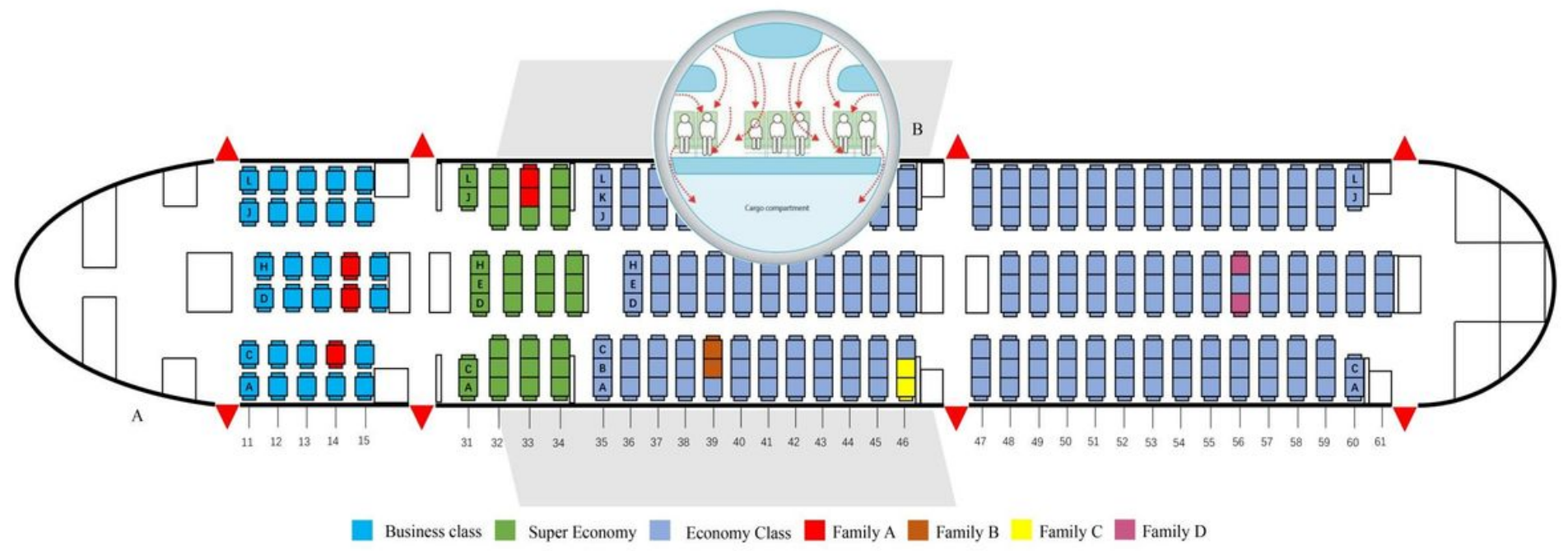

Figure 3

Diagram of the Boeing 787-9 aircraft A: Schematic diagram of seating plan with 11 confirmed cases B: Air circulation pattern in passenger cabin, arrows show air currents from the Lancet22 


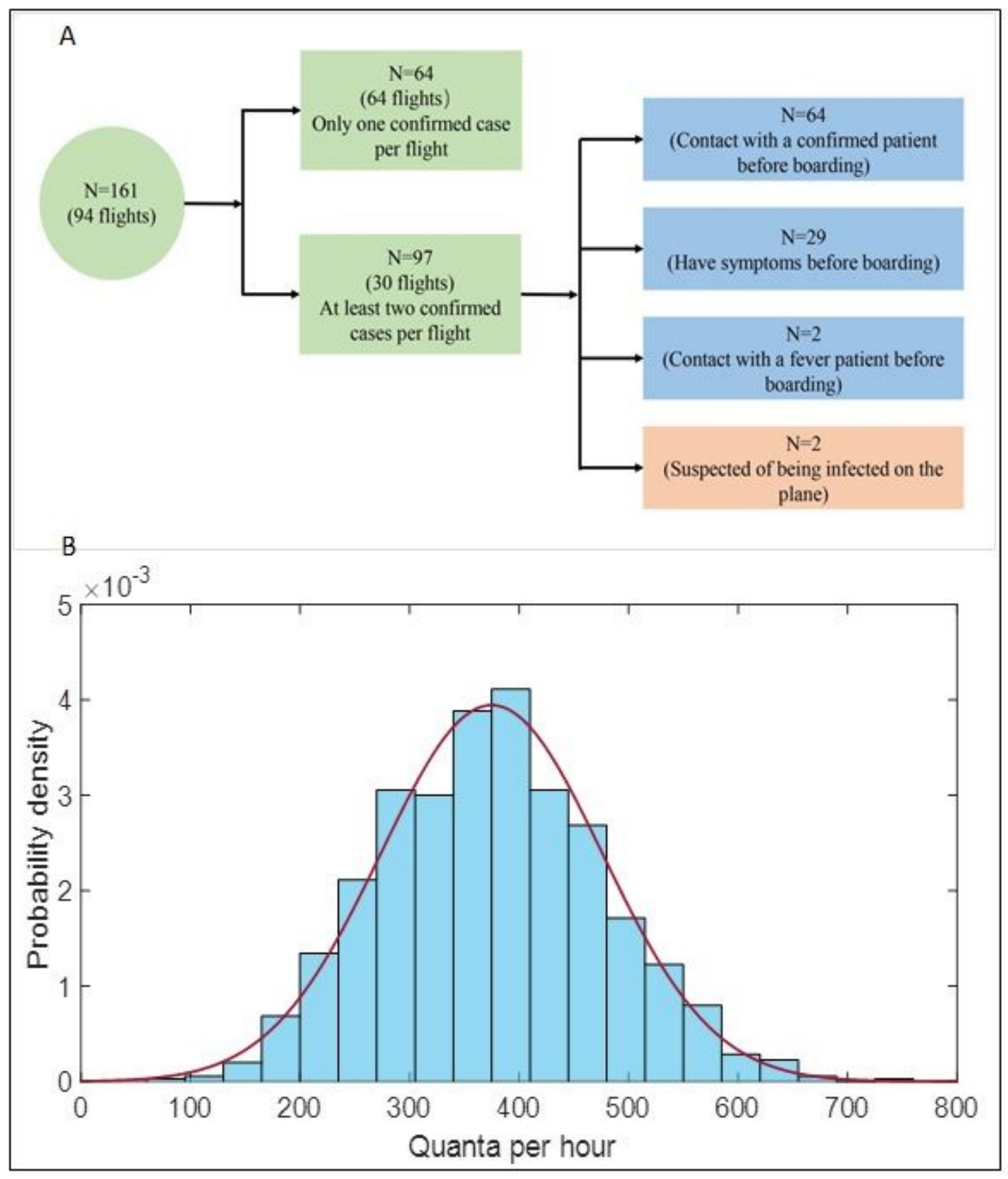

Figure 4

The inference process of the SARS-CoV-2 infectivity in aircraft. (A) The classification of 161 confirmed case . (B) The estimated rate of quanta generation in aircraft. 


\section{A}
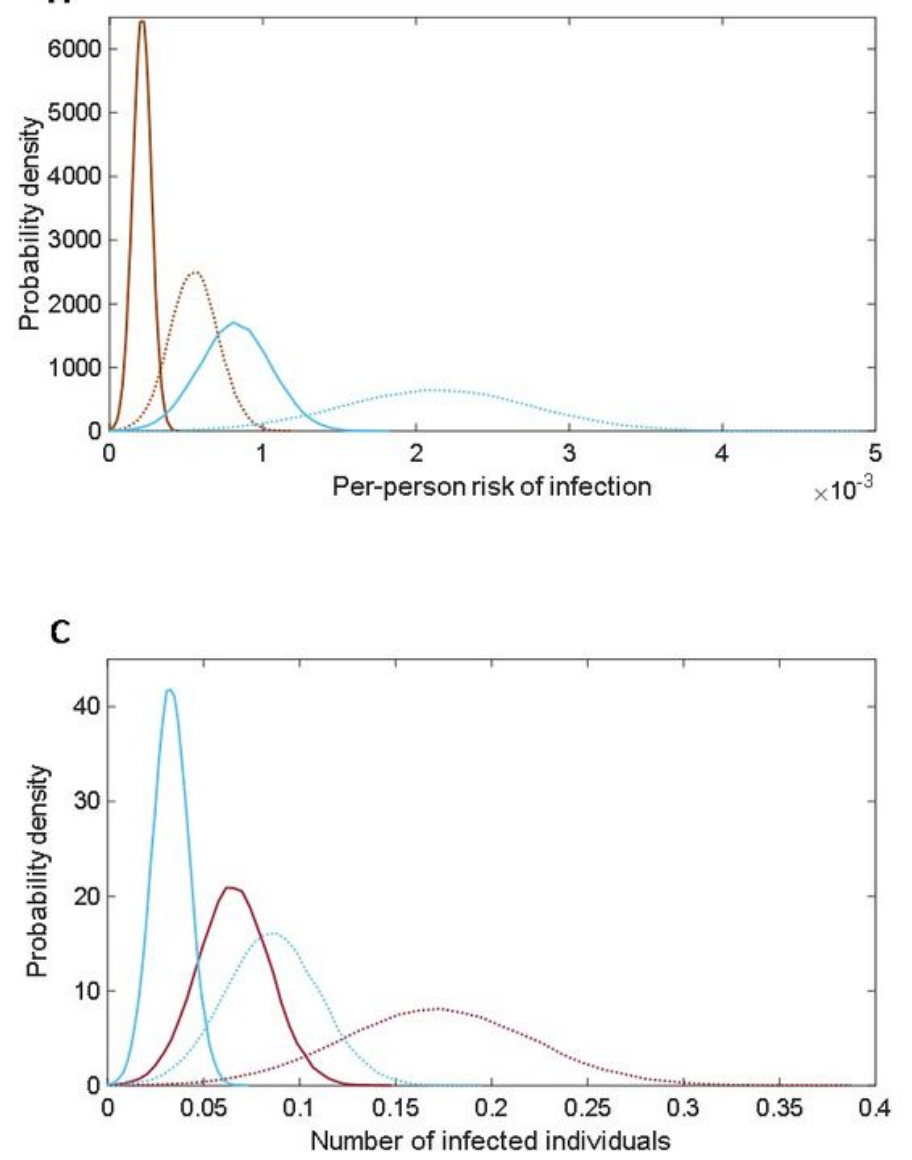

- First class, $5 \mathrm{~h}$ flight $\quad$..... First class, 13h flight
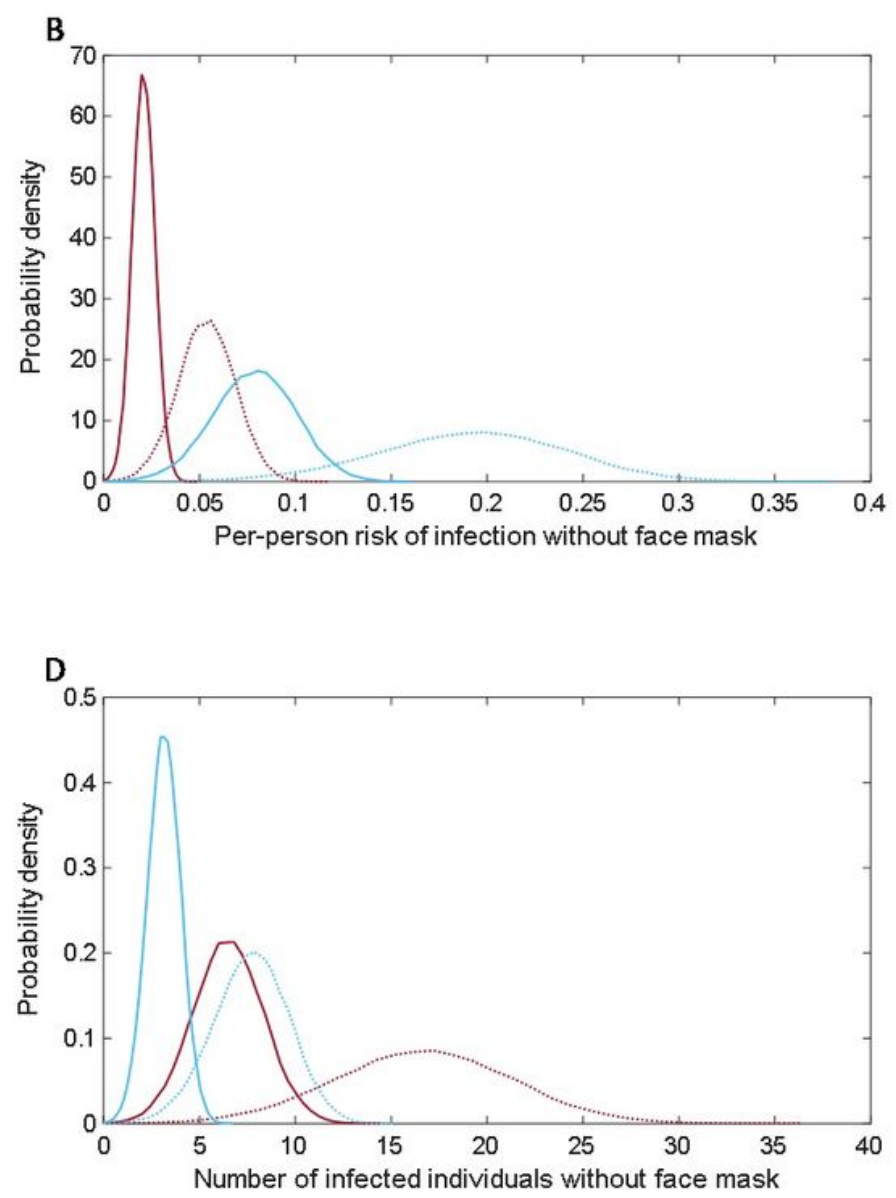

\section{Figure 5}

The predicated transmission of SARS-CoV-2 in aircraft. (A) The per-person risk of infection due to one infector. (B) The per-person risk of infection, assuming without face mask protection. (C) The predicted number of infected individuals due to one infector. (D) The predicted number of infected individuals, assuming without face mask protection. 